\title{
Albania, the human factor and sustainable development: a lesson from the present
}

\author{
Prof. Arta Musaraj
}

Rector of the University "Pavarësia" Vlorë, Albania

\section{Abstract}

Albania as all Balkan countries in general, in the past 20 years faced with deep and continuous socio-economic change which resulted not simply in a totally newly shaped economy, but also in new and unexperienced paths of human resources developments.

This referring to the qualitative, quantitative and diversification terms, brings the age of new professions and connections between the academic development and advancement and the adaption with the real necessities of the labor market.

Adding to this complex and mobile situation the effect on their economy of the last financial crisis, the turbulence level is expected to be increased. Practitioners and researchers must understand connections and make up different scenarios which will face with a very unpredictable environment.

Not surprisingly, Albania as some other southwestern European countries, due to the low level of integration into the international financial market, their mainly domestic market for goods and services produced by them, did not suffer the same consequences as other neighboring countries. But even the effect of downsizing their economies will affect Albanian economy too, because the payment balance and foreign trade balance as well as due to the widening of globalization in its domestic economy, which Albania cannot afford to avoid any longer.

At the same time, the country must take in consideration the economic structure change and its adoption with the EU countries economic structure.

These two main challenges can be afforded with substantial foreign investments and the most attractive resource has proved to be the human one.

Sustainable development of human resources for a national sustainable development, requires making pro-active decision regarding their development and planning. The welfare of countries more and more is not being measured by the GDP pro capita, instead it is being used the term" life quality" which calls for decision making process aiming to increase and not simply exploit, which pro-actively develops qualitative human resources. This because a major factor for development is direct foreign investment. 
This drives Albania as well as other Balkan countries shift from naturally gifted with human resources due to the high nativity toward having attractive human resources in terms of quality and diversity related to actual and future trends of economy structuring and development.

The paper deals with issues related to economic and human development by comparing two major factors in the case of Albania: the quality of human resources, role of foreign investments in the Albanian economic development and effects of human resources have on them and the careful planning of human resources development driven by actual and future trends of economic development. At the same time, the paper analyses the necessity to link the didactic offer of universities and high schools and market driving forces.

Keywords: human resource developement, economic structure, foreign direct investment, learning and training, labor market.

\section{Today's Albanian economic and social development features}

Albania has for a long time been distinguished in terms of demographic development by large internal and external migratory waves started from 1990 up to now, declining mortality rates, and a decline in fertility rates, which have this negative trend staring from '90-s totally different from that one before this period.

These data at the same time testify for a young population in Albania where the average age is estimated to be 28.3 while this figure in Albania is estimated to be 39 in the countries of the European Union. Following with this trend of growth, it is forecasted that up to 2025 the Albanian population will reach the number of 3.66 million

Nevertheless, even this diminishing trend of growth compare to 20 years ago nothing can change the fact that the Albanian population remains the youngest one in Europe.

The way this population relates to the labor market is a specific indicator regarding the analysis of the qualitative aspect of human resources, labor market's trend and needs for investments in human resources development.

There exist a direct positive relation between the economic structure of a country and the amount of direct investments in human resources. In general, the developments on the job market have been characterized by continuous transitions due to the internal processes as well as due to the globalized economy which Albania cannot avoid to be part of.

Referring to a report of the European Training Foundation (ETF) in 2007 the share of agriculture in the Albanian economy, which was almost $20 \%$, significantly exceeded 
the share of industry, which was only $9.5 \%$. Two other important features of the Albanian economy are the prevalence of micro and small-sized enterprises ( $94 \%$ of total enterprises) and the informality of the economy in both rural and urban areas.

The great portion of informality in this market obviously makes the measuring of the impact of unemployment on the skill need's planning very difficult.

The way of defining the economic structure of a country is that of measuring the ratio between the production of the sector and the overall level of the general production usually embodied in the GDP. This kind of economic structuring is called the vertical structuring.

The economic structure does not represent a definitive category. Structural changes can be the aim of development processes itself. The speed and processes to achieve it are affected by a considerable number of factors, particularly from the economic growth and the level of accumulation.

In the case of Albania as well as that of other Balkan countries, there is another standard to match in terms of economic structuring is that of conforming their countries economy with the EU countries economy.

The level of accumulation in the last 20 years in these countries cannot afford restructuring based on their financial resources mainly, this because the low level of industrialization. It is logical that they need a lot of foreign monetary flows and the better way to do it is the increasing of FDI.

They need to be attracted and among other attractions, Human Resources are perhaps the most attractive for a sustainable development.

\section{Defining the objectives of HRD in Albania}

As mentioned above, due to national particularities in the development of the labor market, it becomes a complex challenge.

Human resources are considered to be the principal asset of every country. But the effect of their size and quality is more evident in the local and regional labor markets and therefore by the business which compound these markets.

Even these local mutual effects on human resources Albania face more and more the effect of globalization. Thus, globalization compounds a major constrain on human resources development and represent actually a driving force toward professions and jobs which not necessarily match with future trends and aim regarding HR.

HRD must necessarily address issues such as:

- How policies on HRD support the actual employment schema 
- What kind of opportunities Albania offers for qualitative education and training

- What kind of flexibility the education market offers in terms of gaining new professions and knowledge on the step of the labor market development.

Referring to ETF data, unemployment affected the most people under 34, who make up $60 \%$ of registered job seekers. In 2006, young people aged $15-25$ made up $24 \%$ of the total number of registered job seekers. The unemployment rate is higher in the north-eastern part of the country, reaching around $24 \%$ compared with $13 \%$ in the central and southern area.

Even this fact, at the individual level of an unemployed person, in a time span of 10 years, the same person is unemployed for a period of 3 years.

The reasons for this are difficult to be identified due to the high level of informality and it becomes difficult to distinguish the effect of limited knowledge and skills required by the jobs actually running in the labor market or because the limited growth of jobs and occupation.

Data still report for a high number of unemployed people in the share of who are able to work.

The signing of the agreement with the International Labor Organization (ILO) since 2006 addressed these issues toward this category of unemployed people trying to improve their employment conditions due to improved legislation, increased participation in decision making regarding HRD policies and increased conformity with EU norms.

Planned HRD in Albania needs always donors' support in both directions: the financial one in order to support measures and interventions, as well as experts' assistance is particularly important in the light of the necessary reform due to increased conformity of the country with EU countries' economic structure.

At the same time this calls out for building institutional capacity to plan, activate and control HRD.

\section{Economy structuring, Foreign Direct Investments and HRD in Albania}

In the two last decades, Albania testifies for an increasing dependence from FDI-s as a prime source of capital flows in the country.

This is because they did not simply bring an increased access to foreign exchange, trade and employment, but at the same time they introduced new products, new technologies and more access on information. At the same time, the increasing of FDI-s has been accompanied by an increased investment in HRD and as result of this, more aid and support for the less advantaged groups. 
In cases of success, this has been achieved by a strong engagement of decision makers, institutions and administrations to drive and reinforce the creation of the necessary skills and knowledge through a strong partnership with the private sector, mostly in the fields of the real economy and marginalized categories.

This is a characteristic of multinational companies, taking in consideration that they use to play an active role in HRD mainly in the sectors where they operate, e.g. information technologies, electronics and nutrition.

Unfortunately, in a considerable number of evidences this has not been in the case of Albania.

The education and training sectors did not step aside the actual needs of the labor market and are not yet conforming to future trends or national policies.

\section{Driving forces for the planning of human training and the didactic offer of universities in Albania}

Besides the recognized limitations, HRD in Albania needs to be planned, and present can teach good lessons.

Giving a look at the efforts up to now undertaken there have been two major and significant factors which characterize the development of the knowledge and expertise market.

The first one comes from the aid and assistance of foreign organizations, governments and institutions through programs whose aim was to increase the diversity of knowledge and professions who seemed to be on vogue into the labor market. Efforts such as the Training Program in Health Planning and Management (THPM), Strengthening National Capacities in Policy Formulation, Aid Planning, Programming, Implementation and Monitoring (European Union) of the Maastricht School of Business, EFT program of SEED, IFC part of the WB or the last one, Laboratories of Human Development of ArtGold Albania, UNDP, represent good efforts and support which did in final analysis lack an established framework within which to seek and find the best way to interfere. They tried to set up a logical framework but always by missing to cope with valid information from businesses and enterprises as well as from job seekers, the set of their knowhow or expectations. In many cases, they tried to set up a network of local providers for these services, but the developments in the fields of university diplomas and studies created a real mess in the job seeker choices of where and how to develop their capabilities.

At the same time the DoPA held some training with specific targets, such as in human resource management and training of trainers in European integration issues. The creation of the Training Institute for Public Administration (TIPA) was financed by the 
EU and UNDP. But the role itself of DoPA up until now has been a supervisory one, and TIPA did not have the necessary structural and financial support. Actually, Albania lacks a substantial mass of trained, skilled civil servants whose presence probably will increase the responsiveness and accountability of the PA toward the citizens.

The second one was that of the re-organization of university studies in three cycles by increasing flexibility in order to create more chances to switch on new professional profiles for the people enrolled in university studies, by giving more chances to match with labor market requirements.

It is obvious that they are not oriented by any kind of planning of HRD in the country. In most of cases it is forced by a genuine reading of labor market signs mainly based in personal experiences. It is clear that the HRD long run planning must be proceeded by the set of measures and reforms to be taken in order to make the necessary adaption and transformation of the Albanian economic structure. Of course it calls for coming out a vicious cycle between HRD and economic structuring.

A very important and significant event referring to this argument was the Universities Ranking in Albania. The fact is that only $15 \%$ of the ranked universities did have an Excellent evaluation on the market orientation of the diploma they deliver.

Meanwhile Albania makes its step toward a stable economic structure, people need to decide what knowledge to acquire, what university diploma to achieve and what kind of intensive learning to follow.

This calls for a proactive HRD, which understands future needs by making use of present stories in order to attract more valid foreign investments and make use of their general benefits toward a stable economy as its European counterparts.

\section{Bibliography}

1. Z. Arandjelović, V. Marjanović, D. Djordjević, The change of economic structure of Balkan countries as a condition for integration in European Union, 2007

2. M. Feldstein, An Examination of Causality between Foreign Direct Investment and Human Resource

3. M. Nikolovska, Human Resource Development, Country Analysis, Albania, ETF, 2008

4. Training Programme in Health Planning and Management (THPM), Swiss Agency for Development and Cooperation, Octorber 2008 
5. Albania: Strengthening National Capacities in Policy Formulation, Aid Planning, Programming, Implementation and Monitoring (European Union), Maastricht School of Management,

6. A. Musaraj, J. Gerxhi, Communication and Ethical Behavior in the Public Service, From a moral choice toward a legal code, Academicus, Vol. 1

7. J. Gerxhi, The management of human resource in the local government, Academicus, Vol. 1

8. S. Berdo, Education factor and human resources development, Academicus, Vol. 1

9. Report on Universities Ranking in Albania, MASH, 2011 